Article

\title{
Empirical Kinetic Modelling of the Effect of L-Ascorbic Acid on the Cu(II)-Induced Oxidation of Quercetin
}

\author{
Nikoletta Bobolaki ${ }^{1}$, Angelos Photiades ${ }^{1} \mathbb{D}$, Spyros Grigorakis ${ }^{1}$ and Dimitris P. Makris ${ }^{2, * \mathbb{C}}$ \\ 1 Food Quality \& Chemistry of Natural Products, Mediterranean Agronomic Institute of Chania (M.A.I.Ch.), \\ International Centre for Advanced Mediterranean Agronomic Studies (CIHEAM), P.O. Box 85, \\ 73100 Chania, Greece; bompolaki@maich.gr (N.B.); anp61@aber.ac.uk (A.P.); grigorakis@maich.gr (S.G.) \\ 2 Green Processes \& Biorefinery Group, School of Agricultural Technology, Food Technology \& Nutrition, \\ University of Applied Sciences of Thessaly, 43100 Karditsa, Greece \\ * Correspondence: dmakris@teilar.gr; Tel.: +30-244-106-4792
}

Received: 2 July 2018; Accepted: 29 September 2018; Published: 1 October 2018

check for updates

\begin{abstract}
This study aimed at investigating the effect of L-ascorbic acid on the $\mathrm{Cu}^{2+}$-induced oxidation of quercetin, within a $\mathrm{pH}$ range from 6.7 to 8.3 and temperatures varying from 53 to $87^{\circ} \mathrm{C}$. Initial examinations showed that quercetin degradation obeyed apparent first-order kinetics and it was significantly affected by temperature. Modelling of the effect of L-ascorbic acid by implementing response surface methodology suggested that L-ascorbic acid did not impact quercetin oxidation significantly $(p<0.05)$ and led to an empirical kinetic model based on temperature $(T)$ and $\mathrm{pH}$. Liquid chromatography-diode array-mass spectrometry analyses revealed the presence of typical quercetin degradation and oxidation products, including protocatechuic acid and 2-(hydroxybenzoyl)-2-hydroxybenzofuran-3(2H)-one. It was concluded that the formation of L-ascorbyl or other radicals (superoxide anion) may be involved in quercetin oxidation and this fact merits further attention to illuminate the possible beneficial or adverse nutritional consequences of such reactions in foods.
\end{abstract}

Keywords: L-ascorbic acid; copper(II); oxidation kinetics; quercetin; response surface methodology

\section{Introduction}

Quercetin is a ubiquitous flavonoid that belongs to the subclass of flavonols and may be present in several edible fruits and vegetables [1]. Quercetin is a well-studied molecule owed to its wide range of bioactivities, including chemopreventive action and beneficial effects against other cardiovascular degenerative diseases [2]. This particular flavonoid is also notorious for its powerful antioxidant properties, which, along with other dietary antioxidants such as vitamin C, vitamin E and carotenoids, may provide effective protection against oxidative stress [3].

Quercetin is prone to oxidation, which may be brought about either chemically or enzymatically and, depending on the conditions, quercetin oxidation could yield a spectrum of products, arising from dimerization, skeleton alteration and decomposition [4]. In any case, modification of the structural features of the parent molecule unavoidably leads to modification of the biological properties of quercetin, but this does not always entail complete abolishment of its potency. For example, some degradation products formed following quercetin oxidative cleavage were demonstrated to possess inferior antioxidant activity compared with quercetin itself [5]. Furthermore, a quercetin dimer, generated through quercetin oxidation was also shown to be a less effective antioxidant [6]. To the contrary, another quercetin oxidation product [2-(hydroxybenzoyl)-2-hydroxybenzofuran-3(2H)-one] 
was shown to exhibit improved antioxidant characteristics [7]. More recent data on this particular product were in the same line, revealing a 200-fold higher cytoprotective potency [8].

L-Ascorbic acid (vitamin C) is a well-known food antioxidant that may eliminate a spectrum of oxidising species, such as superoxide anion radical $\left(\mathrm{O}_{2}{ }^{\bullet-}\right)$, hydroxyl radical $\left(\mathrm{OH}^{\bullet}\right)$ and singlet oxygen, due to its ease of oxidation by either a one- or two-electron transfer $[9,10]$. Ascorbic acid may also lower the oxidation state of metals, such as iron and copper, and their valence, thus affecting oxidation catalysis. These unique features make L-ascorbic acid a powerful antioxidant, capable to protect a variety of substrates from oxidation. L-Ascorbic acid may be rapidly oxidised in the presence of bivalent copper $\left(\mathrm{Cu}^{2+}\right)$, but the extent of oxidation may be limited in the presence of metal-chelating flavonoids, such as quercetin [11,12].

However, L-ascorbic acid may also act as an antioxidant in such a system, protecting quercetin from $\mathrm{Cu}^{2+}$-induced oxidative degradation [5]. Therefore, depending on the conditions $(\mathrm{pH}$, temperature, the presence of other redox species, relevant amounts of redox species implicated), in a system containing L-ascorbic acid, quercetin and $\mathrm{Cu}^{2+}$, one antioxidant may be sacrificed at the expense of the other, yet a prediction regarding the eventual shift of such a cascade of reactions would be rather difficult, due to the high complexity. This being the case, this study aimed at modelling the effect of L-ascorbic acid on quercetin stability in the presence of $\mathrm{Cu}^{2+}$, considering the kinetic behaviour of quercetin degradation as a function of $\mathrm{pH}$ and temperature. Following a preliminary investigation, the interactions between L-ascorbic acid and quercetin were modelled by deploying response surface methodology. Tentative characterisation of major quercetin oxidation products using liquid chromatography-mass spectrometry enabled the identification of putative oxidation pathways.

\section{Materials and Methods}

\subsection{Chemicals}

Quercetin dihydrate, L-ascorbic acid, copper(II) chloride dihydrate and citric acid were from Sigma-Aldrich (St. Louis, MO, USA). Di-sodium hydrogen phosphate dihydrate was from Merck (Darmstadt, Germany). Stock solution of quercetin $(20 \mathrm{mM})$ was prepared in acetone and stored at $-20^{\circ} \mathrm{C}$. Stock solution of copper(II) chloride $(20 \mathrm{mM})$ was prepared in $0.05 \mathrm{M} \mathrm{HCl}$ and stored at $4{ }^{\circ} \mathrm{C}$. Stock solution of L-ascorbic acid $(5 \mathrm{mM})$ was prepared exactly before used in double-distilled water. All solvents used for liquid chromatography-mass spectrometry were of HPLC grade.

\subsection{Treatment, Sampling and UV-Vis Measurements}

For the preliminary experiments, an aliquot of $30 \mathrm{~mL}$ of phosphate-citrate buffer (50 mM, pH 7.0), was placed in a $50 \mathrm{~mL}$ glass reaction vial and spiked with an appropriate volume of a quercetin stock solution and copper(II) chloride stock solution, to give corresponding final concentrations of 33.3 and $66.6 \mu \mathrm{M}$. The mixture was under constant magnetic stirring at $300 \mathrm{rpm}$ and heated up at $70^{\circ} \mathrm{C}$. Constant temperature was provided by immersing the reaction vial in oil bath, heated by a precisely thermostated hot plate (YellowLine MST Basic C, Richmond, VA, USA). Sampling was accomplished by withdrawing aliquots of $1 \mathrm{~mL}$ at regular intervals ( 5 to $40 \mathrm{~min}$ ). After withdrawal, the sample was placed in $1.5 \mathrm{~mL}$ Eppendorf tube and cooled down with tap water. The cooled sample was transferred immediately to a $1 \mathrm{~mL}$ quartz cell and the absorbance of the A-band maximum of quercetin (Figure 1) was obtained for tracing kinetics. Following measurements, the sample was returned to the reaction vial to maintain the initial headspace volume. For the response surface methodology, the $\mathrm{pH}$ of the reaction mixtures and the reaction temperature were adjusted as dictated by the experimental design. The concentration of L-ascorbic acid in the reaction mixture, also defined by the experimental design, was adjusted by spiking the mixture with appropriate volume of the L-ascorbic acid stock solution. 


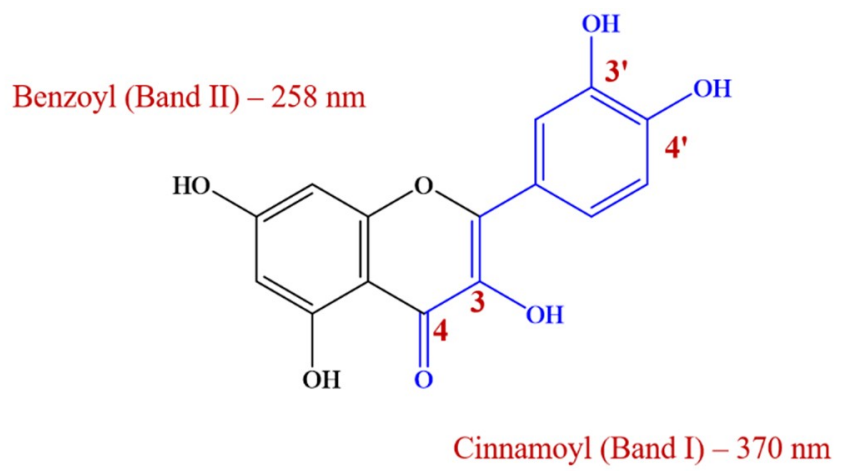

Figure 1. Quercetin structure and assignment of characteristic absorption maxima to specific structural features.

\subsection{Large-Scale Treatment and Sample Preparation}

A phosphate-citrate buffer solution (50 mM, pH 7.5) was spiked with appropriate volumes of quercetin, $\mathrm{Cu}^{2+}$ and L-ascorbic acid to give final concentrations of 333,666 and $400 \mu \mathrm{M}$, respectively. This solution was heated at $87^{\circ} \mathrm{C}$ for $40 \mathrm{~min}$ and then it was cooled down to ambient temperature with tap water. A volume of $15 \mathrm{~mL}$ of the solution was adjusted to $\mathrm{pH} 1$ with $6 \mathrm{~N} \mathrm{HCl}$ and then extracted in a separatory funnel three times with $15 \mathrm{~mL}$ ethyl acetate:diethyl ether (8:2). The extracts were pooled and taken to dryness in a rotavapor (Büchi Rotavapor R-114, Merck), at $40^{\circ} \mathrm{C}$. The residue was dissolved in $1.5 \mathrm{~mL}$ methanol and this sample was used for chromatographic analyses.

\subsection{Experimental Design}

The purpose of the assay was to evaluate the effect of L-ascorbic acid on the stability of quercetin in the presence of $\mathrm{Cu}^{2+}$, as a function of L-ascorbic acid concentration $\left(C_{\mathrm{AA}}\right)$, temperature $(T)$ and $\mathrm{pH}$. The stability of quercetin was estimated by calculating the apparent first-order decay constant $k$, by tracing kinetics. Thus, $k$ was considered as the response. To simultaneously assess the influence of the three variables, a central composite design - uniform precision methodology with six central points was deployed. The independent variables were coded between -1.682 (lower limit) and +1.682 (upper limit), using the following equation:

$$
x_{i}=\frac{X_{i}-X_{0}}{\Delta X_{i}}, i=1,2,3 .
$$

Terms $x_{i}$ and $X_{i}$ correspond to the dimensionless and the actual value of the independent variable $i$. The term $X_{0}$ is the actual value of the independent variable $i$ at the central point of the design, and $\Delta X_{i}$ the step change of $X_{i}$ (Table 1). The choice for the range of values for all variables was based on preliminary runs and previous data [5]. ANOVA was carried out to estimate model significance, the significance for each polynomial coefficient, and determine the overall coefficient $R^{2}$ for the mathematical model. Statistically non-significant dependent terms $(p>0.05)$ were not considered in the models and were omitted. The models were validated by carrying out runs using the predicted optimal conditions and comparing the predicted values with the actual (measured) ones.

Table 1. Actual and coded values of all three independent variables considered for the experimental design.

\begin{tabular}{ccccccc}
\hline Independent Variable & Code & \multicolumn{5}{c}{ Coded Variable Level } \\
\hline & & -1.682 & -1 & 0 & 1 & 1.682 \\
$C_{\mathrm{AA}}(\mu \mathrm{M})$ & $X_{1}$ & 6.4 & 20 & 40 & 60 & 73.6 \\
$\mathrm{pH}$ & $X_{2}$ & 6.7 & 7 & 7.5 & 8 & 8.3 \\
$T\left({ }^{\circ} \mathrm{C}\right)$ & $X_{3}$ & 53 & 60 & 70 & 80 & 87 \\
\hline
\end{tabular}




\subsection{Liquid Chromatography-Diode Array-Mass Spectrometry (LC-DAD-MS)}

A Finnigan (San Jose, CA, USA) MAT Spectra System P4000 pump, coupled with a UV6000LP diode array detector and a Finnigan AQA mass spectrometer was employed. Chromatography was carried out on a Fortis RP- 18 column, $150 \mathrm{~mm} \times 2.1 \mathrm{~mm}, 3 \mu \mathrm{m}$, at $40{ }^{\circ} \mathrm{C}$. Mass spectra were acquired with electrospray ionization (ESI) in positive ion mode, with probe temperature $350{ }^{\circ} \mathrm{C}$, acquisition 10 and $50 \mathrm{eV}$, source voltage $25 \mathrm{~V}$, capillary voltage $4 \mathrm{kV}$ and detector voltage $650 \mathrm{~V}$. The eluents were (A) $1 \%$ acetic acid and (B) methanol. The flow rate was $0.2 \mathrm{~mL} \cdot \mathrm{min}^{-1}$, and the elution programme used was from 0 to $10 \% \mathrm{~B}$ in $2 \mathrm{~min}$; from 2 to $22 \mathrm{~min}, 100 \% \mathrm{~B}$; from 22 to $27 \mathrm{~min}, 100 \% \mathrm{~B}$; and then back to initial conditions within $5 \mathrm{~min}$.

\subsection{Statistics}

Each experiment was carried out at least twice and each measurement at least three times. The values reported are means \pm standard deviation. The experimental design and all relevant statistical analyses were performed with JMP TM Pro 13 (SAS, Cary, NC, USA). Curve fitting for estimating kinetic models was performed using SigmaPlot ${ }^{\mathrm{TM}} 12.5$ (Systat Software Inc., San Jose, CA, USA), at least at a $95 \%$ significance level $(p<0.05)$.

\section{Results and Discussion}

\subsection{Initial Spectrophotometric Examination}

The flavonoid skeleton of quercetin (Figure 1) exhibits a distinct $\lambda_{\max }$ in methanol, at $370 \mathrm{~nm}$ (Band I) [13]. On the other hand, quercetin oxidative degradation leads in the formation of simple phenolics that possess uniformly low absorbance at this region of the spectrum [14]; thus, quercetin degradation may be effectively monitored by recording $\mathrm{A}_{370}$, without perturbation. However, quercetin is an efficient metal chelator and complexation with $\mathrm{Cu}^{2+}$ has been shown to provoke a bathochromic shift in $\lambda_{\max }$. In methanol, complexation of $\mathrm{Cu}^{2+}$ by the $3-\mathrm{OH}$ and the $4-\mathrm{C}=\mathrm{O}$ group may lead in a $\lambda_{\max }$ shift at $436 \mathrm{~nm}$ [15], but upon addition of a complexing agent such as EDTA, the initial $\lambda_{\max }$ is almost completely restored. In a phosphate buffer at pH 7.4, a shift at $460 \mathrm{~nm}$ has been reported and attributed to a quercetin: $\mathrm{Cu}^{2+} 1: 1$ complex [16].

Quercetin $(33.3 \mu \mathrm{M})$ in phosphate-citrate buffer at $\mathrm{pH} 7.5$ exhibited $\lambda_{\max }$ at 372 and $258 \mathrm{~nm}$ and upon addition of $\mathrm{Cu}^{2+}$ and L-ascorbic acid at a quercetin: $\mathrm{Cu}^{2+}:$ L-ascorbic acid molar ratio of 1:2:1.8, no bathochromic shift was observed. It should be noted that the lack of bathochromic shift in the UV-vis spectrum of quercetin upon chelation with $\mathrm{Cu}^{2+}$ has also been reported by other authors [17]. At this point, the effect of $\mathrm{pH}$ should also be considered. While up to $\mathrm{pH} 7.4$ the shift observed in Band I absorption is limited to a few $\mathrm{nm}$, at $\mathrm{pH} 8.6$ this shift may reach up to $25-30 \mathrm{~nm}$, owing to the deprotonation of the B-ring $\mathrm{OH}$ groups [18]. Indeed, at $\mathrm{pH} 8.3$ quercetin displayed a bathochromic shift for both Bands I and II, having $\lambda_{\max }$ at 390 and $269 \mathrm{~nm}$.

\subsection{Preliminary Oxidation Kinetics and Temperature Effects}

Early studies on quercetin oxidation demonstrated that this reaction obeyed apparent first-order kinetics [19]:

$$
\mathrm{u}=k[\mathrm{Qt}] \text {, }
$$

where $k$ is the experimentally determined reaction rate constant $\left(\mathrm{min}^{-1}\right)$ and [Qt] the molar concentration of quercetin. The reaction was shown to be $\mathrm{pH}$-depended within a $\mathrm{pH}$ range from 4.1 to 7, exhibiting a linear correlation between $k$ and $\mathrm{pH}$. Such a phenomenon was further confirmed by more recent examinations, which showed a $\mathrm{pH}$-depended degradation of quercetin within a narrower $\mathrm{pH}$ region of 6 to 7.5 , at $37^{\circ} \mathrm{C}$, but also a temperature-dependent increase in $k$, within a range of 37 to $65^{\circ} \mathrm{C}$ [20]. In the same line, latter investigations showed that $\mathrm{Cu}^{2+}$-induced quercetin oxidation at $\mathrm{pH} 8$ and $97^{\circ} \mathrm{C}$ also displayed first-order kinetics, with $k$ being linearly correlated 
with $\left[\mathrm{Cu}^{2+}\right]$ [14]. Under these conditions, L-ascorbic acid was proven to inhibit quercetin oxidative degradation significantly $(p<0.05)$, when added at a quercetin: L-ascorbic acid molar ratio of 2 [5].

On this ground, preliminary experiments were carried out to draw information for the kinetic behaviour of quercetin degradation in a citrate-phosphate buffer. First, it was tested the effect of temperature by performing kinetic assays at both 50 and $90{ }^{\circ} \mathrm{C}$ and $\mathrm{pH} 7$, with a quercetin: $\mathrm{Cu}^{2+}$ molar ratio of 2 (Figure 2a). Using SigmaPlot ${ }^{\mathrm{TM}} 12.5$, the model best fitted to experimentally obtained data was pseudo first-order kinetics, described as follows:

$$
\mathrm{A}_{367(t)}=\mathrm{A}_{367(0)} e^{-k t}
$$

$\mathrm{A}_{367(t)}$ represents the absorbance at $367 \mathrm{~nm}$ at any time $t(\mathrm{~min}), \mathrm{A}_{367(0)}$ the initial absorbance and $k\left(\mathrm{~min}^{-1}\right)$ the apparent first-order decay constant. The absorbance at $367 \mathrm{~nm}$ was used because, under the conditions employed, it was found to be the $\lambda_{\max }$ of quercetin Band I. The linearised form of Equation (3) would be:

$$
\ln \mathrm{A}_{367(t)}=\ln \mathrm{A}_{367(0)}-k t
$$

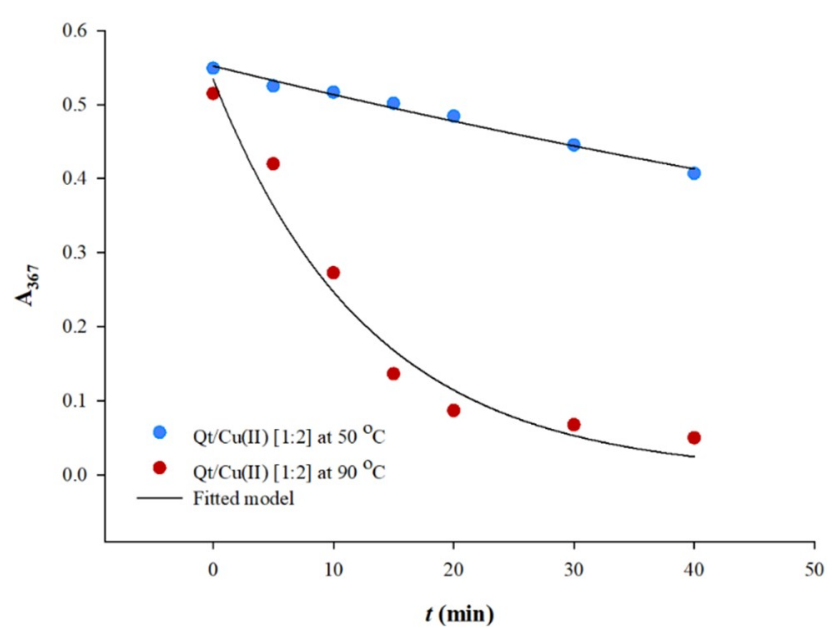

(a)

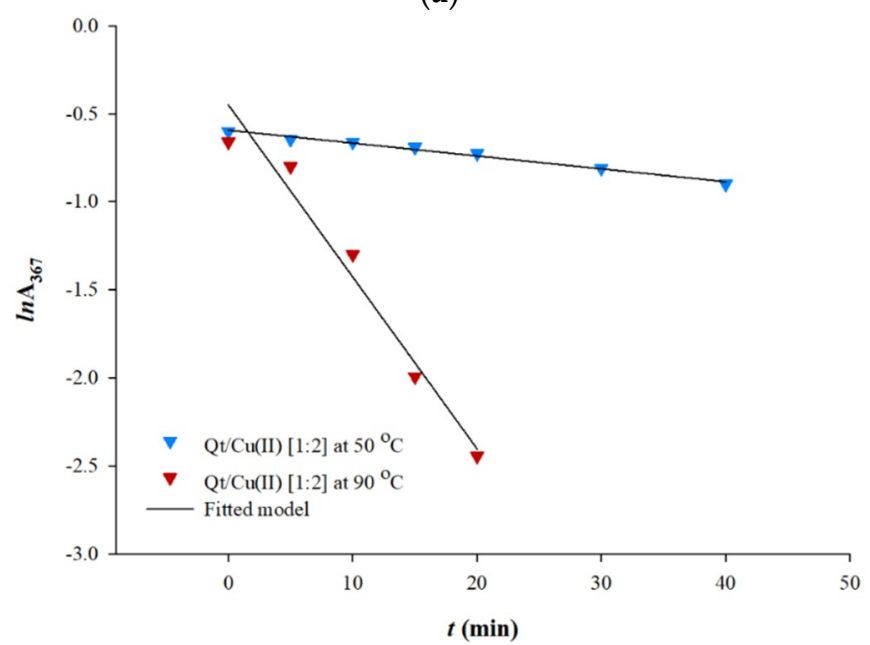

(b)

Figure 2. Kinetics of quercetin oxidation $(33.3 \mu \mathrm{M})$ at $\mathrm{pH} 7$ in the presence of $66.6 \mu \mathrm{M}$ of $\mathrm{Cu}^{2+}(\mathbf{a})$ and verification of pseudo first-order kinetics shown by linear plots $(\mathbf{b})$. 
A plot of $\ln \mathrm{A}_{367(t)}$ against $t$ is a straight line with the slope equal to $-k$ (Figure $2 b$ ). The half-life $\left(t_{\frac{1}{2}}\right)$ of quercetin could then be calculated:

$$
t_{1 / 2}=\frac{0.693}{k}
$$

The graphical determination of $k$ at 50 and $90{ }^{\circ} \mathrm{C}$ gave corresponding values of 0.0073 and $0.0771 \mathrm{~min}^{-1}$. The half-lives determined using the Equation (5) were 94.9 and $9 \mathrm{~min}$, respectively. These findings suggested a significant dependence of quercetin degradation on temperature. To confirm this, the activation energy $\left(E_{a}\right)$ of the reaction was determined as follows [21]:

$$
\ln \left(\frac{k_{2}}{k_{1}}\right)=\left(-\frac{E_{a}}{R}\right)\left(\frac{1}{T_{2}}-\frac{1}{T_{1}}\right)
$$

where $k_{1}$ and $k_{2}$ are the quercetin first-order decay constants at 50 and $90{ }^{\circ} \mathrm{C}$, respectively, $R$ the universal gas constant $\left(8.314 \mathrm{~J} \cdot \mathrm{K}^{-1} \cdot \mathrm{mol}^{-1}\right)$ and $T_{1}$ and $T_{2}$ the temperatures 50 and $90{ }^{\circ} \mathrm{C}$, expressed in $\mathrm{K}$. The $E_{a}$ thus estimated was $59.39 \mathrm{~kJ} \cdot \mathrm{mol}^{-1}$, illustrating a significant dependence on $T$.

When the kinetics was investigated in the presence of L-ascorbic acid (Figure 3a), $\lambda_{\max }$ was recorded at $390 \mathrm{~nm}$ and the model best fitted to the kinetic data was:

$$
\mathrm{A}_{390(t)}=\mathrm{A}_{390(i)}+\mathrm{a} e^{-k t} .
$$

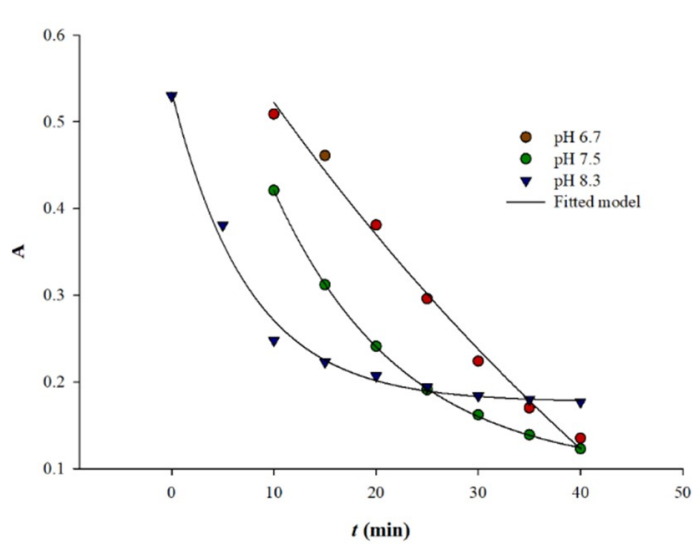

(a)

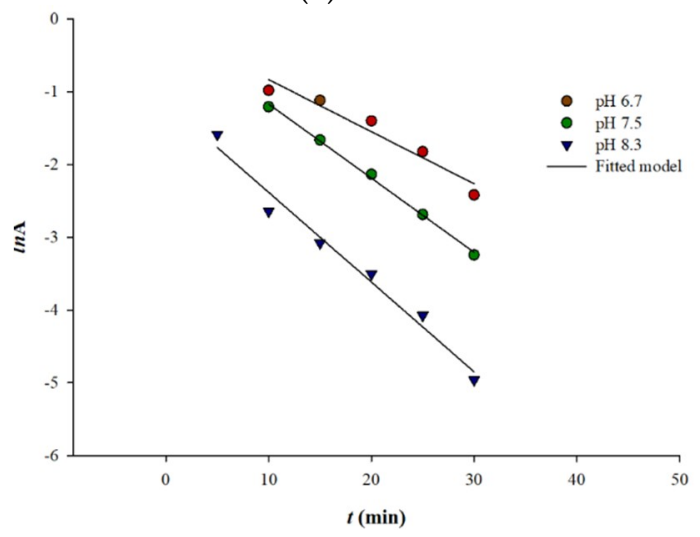

(b)

Figure 3. Effect of $\mathrm{pH}$ on the kinetics of quercetin oxidation $(33.3 \mu \mathrm{M})$ in the presence of $66.6 \mu \mathrm{M}$ of $\mathrm{Cu}^{2+}(\mathbf{a})$ and verification of pseudo first-order kinetics shown by linear plots (b). Reactions were performed in the presence of $40 \mu \mathrm{ML}$-ascorbic acid and $\mathrm{T}=70^{\circ} \mathrm{C}$. 
In Equation (7), $a$ is a fitting parameter and $A_{390(i)}$ the absorbance at infinite reaction time. For simplicity, $\mathrm{A}_{390(i)}$ was considered the absorbance at the end of the assay (40 $\left.\mathrm{min}\right)$. Linearisation of Equation (7) would yield:

$$
\ln \left(\mathrm{A}_{390(t)}-\mathrm{A}_{390(i)}\right)=\ln \mathrm{a}-k t .
$$

A plot of $\ln \left(\mathrm{A}_{390(t)}-\mathrm{A}_{390(i)}\right)$ as a function of $t$ would give a straight line with a slope equal to $-k$ (Figure $3 \mathrm{~b}$ ). To ascertain whether $\mathrm{pH}$ could affect kinetics, experiments were carried out at $\mathrm{pH}$ 6.7, 7.5 and 8.3 at a constant temperature of $70^{\circ} \mathrm{C}$, and in all cases Equation (7) was the model with the highest statistical significance $\left(R^{2}>0.97\right)$. For $\mathrm{pH} 6.7,7.5$ and 8.3 the corresponding $k$ determined were $0.0143,0.0806$ and $0.1335 \mathrm{~min}^{-1}$. This fact pointed to the $\mathrm{pH}$ dependence of $k$.

\subsection{Response Surface Modelling}

The evidence emerged from the preliminary investigation suggested that $k$ may be strongly affected by both $\mathrm{pH}$ and $T$, yet the role of $C_{\mathrm{AA}}$ was unclear. To reveal the combined effects of these three variables, a central composite design-uniform precision methodology was employed. This experimental design allowed for the monitoring of the response $(k)$ in relation with simultaneous variation of all three variables and permitted the detection of possible cross effects. The trends recorded were visualised in 3D plots (Figure 4). By using the desirability function, it was possible to estimate the combination of the three independent variables that would yield maximum $k$ (Figure 5), and this also enabled the prediction of conditions under which maximum $k$ could be attained. After omitting all non-significant terms (Figure 5, inset table), the mathematical model was:

$$
k\left(\min ^{-1}\right)=0.0288+0.0138 X_{2}+0.0224 X_{3}-0.0225 X_{2} X_{3}+0.0236 X_{2}^{2}\left(R^{2}=0.92, p=0.0003\right) .
$$
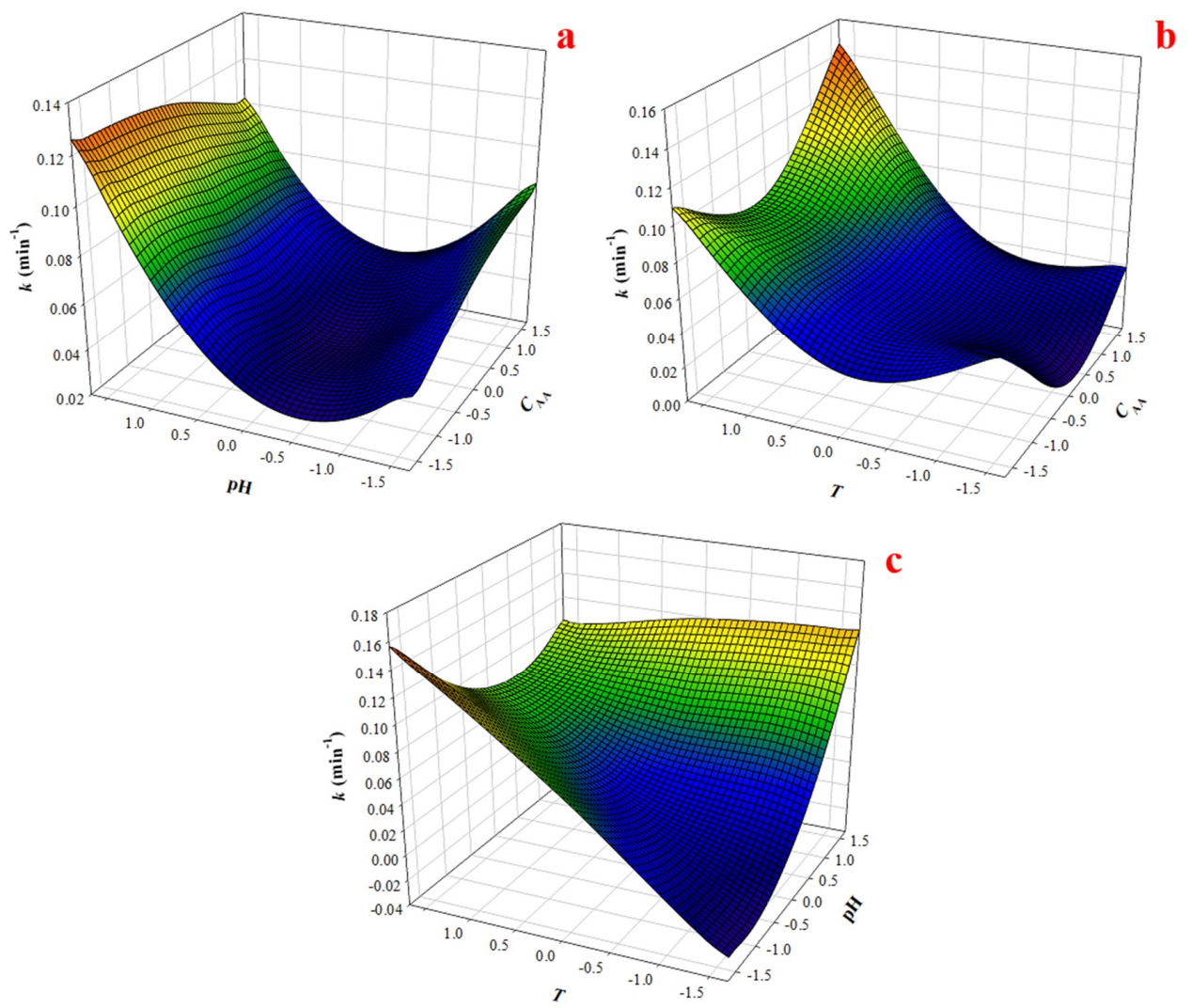

Figure 4. 3D plots illustrating the effect of the simultaneous variation in (a) $\mathrm{pH}$ and $C_{\mathrm{AA}},(\mathbf{b}) T$ and $C_{\mathrm{AA}}$ and (c) $\mathrm{pH}$ and $\mathrm{T}$ on $k$. 


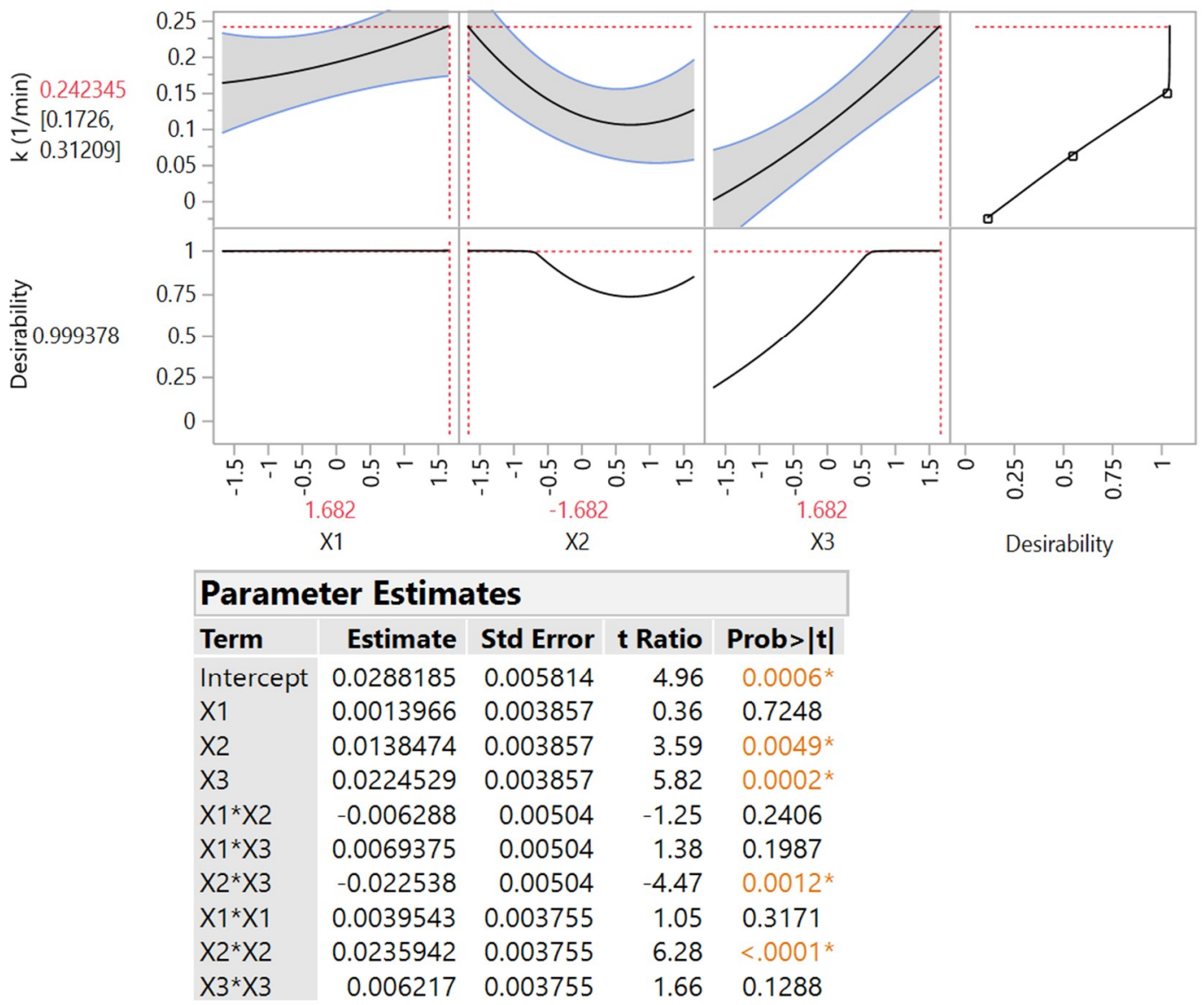

Figure 5. Desirability function and parameter estimates (inset table) determined after implementing a central composite design-uniform precision methodology. Asterisk ${ }^{*}$ ) denotes statistically significant terms.

Out of the three independent variables considered, $\mathrm{pH}$ and $T$ were significant and positively affected $k$, but $C_{\mathrm{AA}}$ was not. This outcome showed clearly that any increase in either $\mathrm{pH}$ or $T$ up to the limits defined by the model, would accelerate quercetin degradation. The negative effect of the cross term $X_{2} X_{3}$ indicated that acceleration of quercetin due to increased $\mathrm{pH}$ could be compensated by lowering $T$ and vice versa. Since no cross terms involving $X_{1}$ were significant, acceleration of quercetin degradation by switching either $\mathrm{pH}$ or $T$ at higher values could not be regulated by modifying $C_{\text {AA }}$ (Table 2). Therefore, under the conditions used, the presence of L-ascorbic acid could only contribute towards accelerating or inhibiting quercetin degradation, indirectly. By setting $\mathrm{pH}$ and $T$ at their corresponding optimum values 6.7 and $87^{\circ} \mathrm{C}$, the theoretical maximum $k$ was estimated to be $0.2423 \pm 0.0697 \mathrm{~min}^{-1}$ (Figure 5).

The finding that L-ascorbic acid had no obvious effect on quercetin oxidation was rather a paradox, in the light of previous examinations that demonstrated a decline in quercetin degradation rate at $\mathrm{pH} 8$ and $97^{\circ} \mathrm{C}$, more than 7 -fold, when L-ascorbic was added at a quercetin/L-ascorbic molar ratio of 2 [5]. Apparently, the relative amounts of all redox species implicated $\left(\mathrm{Cu}^{2+}, \mathrm{L}\right.$-ascorbic acid, quercetin) may play a crucial role in this regard and switching the concentration of any of them could impact the system in a differentiated manner. However, redox potentials and the effect of $\mathrm{pH}$ are prominent factors involved in the relevant reactions and the thorough investigation of their involvement might be the key to understanding the behaviour observed.

First, it should be noted that quercetin has lower oxidation potential $\left(E_{\mathrm{p}}\right)$ than L-ascorbic acid, their corresponding values being 91 and $127 \mathrm{mV}$ [22]. Therefore, it could be supported that quercetin would be preferentially oxidised by $\mathrm{Cu}^{2+}$. In this case, it could be simply argued that this is the reason 
for the apparently non-significant effect of L-ascorbic acid on $k$. Indeed, in a tertiary system containing $\mathrm{L}$-ascorbic acid, $\mathrm{Cu}^{2+}$ and quercetin, the flavonoid acted as a protecting agent against L-ascorbic acid oxidation [23-25], a fact attributed to the chelating ability of quercetin. This was because the oxidation of L-ascorbic acid by $\mathrm{Cu}^{2+}$ was assumed to be mediated by monohydroascorbate $/ \mathrm{Cu}^{2+}$ complex [24], whose formation was presumably inhibited by quercetin.

Table 2. Measured and predicted values of $k$ at all design points used for the response surface methodology.

\begin{tabular}{cccccc}
\hline \multirow{2}{*}{ Design Point } & \multicolumn{2}{c}{ Independent Variable Level } & \multicolumn{2}{c}{ Response $\left(\boldsymbol{k}, \mathbf{m i n}^{-\mathbf{1}}\right)$} \\
\cline { 2 - 6 } & $\boldsymbol{X}_{\mathbf{1}}$ & $\boldsymbol{X}_{\mathbf{2}}$ & $\boldsymbol{X}_{\mathbf{3}}$ & Measured & Predicted \\
\hline 1 & -1 & -1 & -1 & 0.0019 & 0.0030 \\
2 & -1 & -1 & 1 & 0.0871 & 0.0791 \\
3 & -1 & 1 & -1 & 0.0700 & 0.0883 \\
4 & -1 & 1 & 1 & 0.0769 & 0.0743 \\
5 & 1 & -1 & -1 & 0.0002 & 0.0045 \\
6 & 1 & -1 & 1 & 0.1250 & 0.1084 \\
7 & 1 & 1 & -1 & 0.0550 & 0.0647 \\
8 & 1 & 1 & 1 & 0.0778 & 0.0784 \\
9 & -1.682 & 0 & 0 & 0.0421 & 0.0377 \\
10 & 1.682 & 0 & 0 & 0.0403 & 0.0424 \\
11 & 0 & -1.682 & 0 & 0.0600 & 0.0723 \\
12 & 0 & 1.682 & 0 & 0.1335 & 0.1188 \\
13 & 0 & 0 & -1.682 & 0.0277 & 0.0086 \\
14 & 0 & 0 & 1.682 & 0.0675 & 0.0842 \\
15 & 0 & 0 & 0 & 0.0256 & 0.0288 \\
16 & 0 & 0 & 0 & 0.0215 & 0.0288 \\
17 & 0 & 0 & 0 & 0.0254 & 0.0288 \\
18 & 0 & 0 & 0 & 0.0401 & 0.0288 \\
19 & 0 & 0 & 0 & 0.0300 & 0.0288 \\
20 & 0 & 0 & 0 & 0.0321 & 0.0288 \\
\hline
\end{tabular}

On the other hand, the progression of the phenomenon as a function of $\mathrm{pH}$ was rather obscure. Although at low temperature increased $k$ was recorded for high $\mathrm{pH}$, when the temperature was raised to the maximum value defined by the experimental design $\left(87^{\circ} \mathrm{C}\right)$, maximisation of $k$ occurred at pH 6.7 (Figure 4c). It could be postulated that at $53{ }^{\circ} \mathrm{C}$, quercetin $/ \mathrm{Cu}^{2+}$ complex is more stable, representing the main pathway of quercetin oxidation. By contrast, high temperatures might provide the appropriate energy required to destabilise such a complex, giving rise to interactions of $\mathrm{Cu}^{2+}$ with $\mathrm{L}$-ascorbic acid. Should this be the case, the increased $k$ observed might be ascribed to oxidising species formed through $\mathrm{Cu}^{2+} / \mathrm{L}$-ascorbic acid interactions. Indeed, it has long been known that $\mathrm{Cu}^{2+}$ can oxidise L-ascorbic acid as follows $[25,26]$ :

$$
\mathrm{AH}_{2}+\mathrm{Cu}^{2+} \rightarrow \mathrm{Cu}^{+}+\mathrm{AH}^{\bullet}+\mathrm{H}^{+},
$$

where $\mathrm{AH}_{2}$ represents L-ascorbic acid. Should the reaction (i) take place, quercetin degradation could be stimulated by the generation of $\mathrm{Cu}^{+}$. This is because $\mathrm{Cu}^{+}$is more effective than $\mathrm{Cu}^{2+}$ in inducing quercetin oxidation [16]. Given that organic radicals may initiate oxygenation of flavonols by dioxygen [27], then reaction of $\mathrm{AH}^{\bullet}$ with quercetin could be another possible cause of the faster quercetin degradation. Furthermore, once $\mathrm{Cu}^{+}$is formed, then another reaction would be possible:

$$
\mathrm{Cu}^{+}+\mathrm{O}_{2} \rightarrow \mathrm{Cu}^{2+}+\mathrm{O}_{2}{ }^{\bullet-} \text {. }
$$

The superoxide anion radical $\left(\mathrm{O}_{2}{ }^{\bullet-}\right)$ could then react with quercetin in a manner simulating quercetinase (dioxygenase) oxidation [28], giving rise to the depside (DP) and possibly to its decomposition products (a) and (b) [29] (Figure 6). 


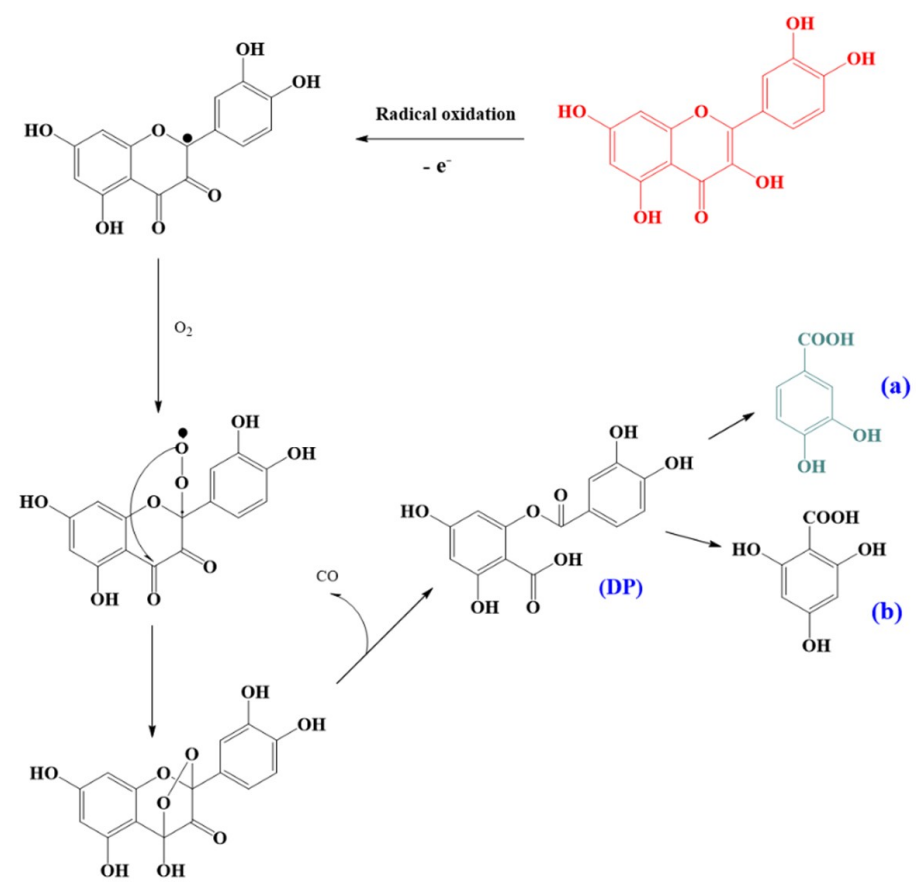

Figure 6. Putative pathway of radical-mediated quercetin oxidation. (DP) depside; (a) protocatechuic acid (3,4-dihydroxybenzoic acid); (b) phloroglucinol carboxylic acid (2,4,6-trihydroxybenzoic acid).

\subsection{Oxidation Products and Putative Pathways}

To substantiate any of the putative pathways proposed, LC-DAD-MS analyses were performed to tentatively identify oxidation/degradation products of quercetin. In Figure 7 it can be seen that two major substances were detected in the sample that exhibited the highest $k$ (sample \#12, Table 2). The presence of protocatechuic acid (product (a), Figure 6) was affirmed by its molecular ion at $m / z=155$. This compound is a typical quercetin degradation product and may be formed under a variety of conditions, including $\mathrm{Fe}^{2+}$ and $\mathrm{Cu}^{2+}$-induced thermal degradation [14], electrochemical oxidation $[4,30,31]$, autoxidation $[4,32,33]$, and radical oxidation $[4,5]$.

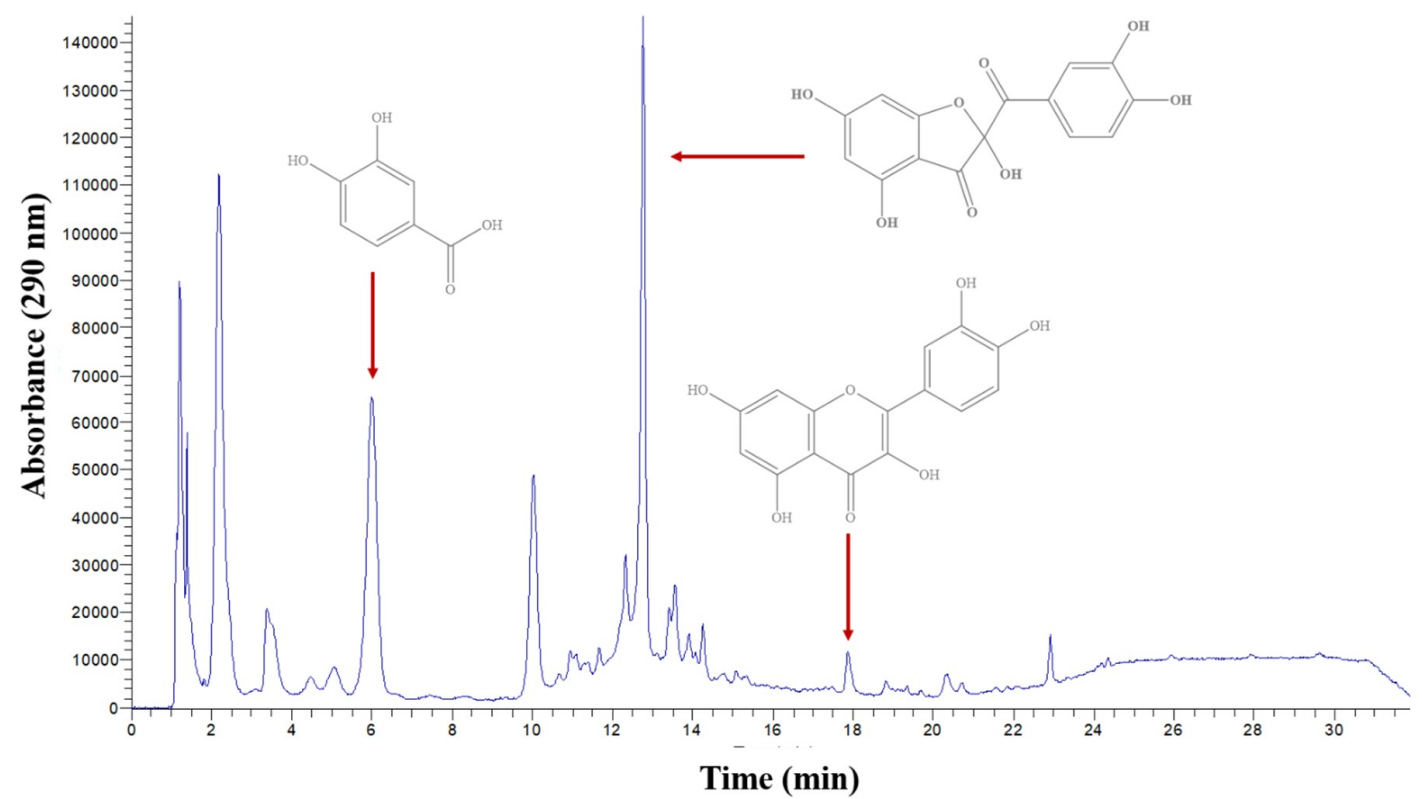

Figure 7. Chromatogram of sample \#12 (see Table 2), monitored at $290 \mathrm{~nm}$. 
In every case, a mechanism implicating the cascade of reactions shown in Figure 6 was postulated, pointing to a radical-mediated oxidation mechanism. However, it has been demonstrated that $\mathrm{Cu}^{2+}$-mediated quercetin oxidation did not generate protocatechuic acid, which was formed only in the presence of $\mathrm{H}_{2} \mathrm{O}_{2}$ [5]. Therefore, considering that Reaction (11) took place, the presence of $\mathrm{H}_{2} \mathrm{O}_{2}$ was rather likely as follows [34]:

$$
\mathrm{Cu}^{+}+\mathrm{O}_{2}{ }^{\bullet-} \rightarrow \mathrm{Cu}^{2+}+\mathrm{H}_{2} \mathrm{O}_{2} \text {. }
$$

On the other hand, the tentative identification of compound (f) (Figure 8), based on its pseudo molecular ion at $m / z=319$ and a diagnostic $\mathrm{Na}^{+}$adduct at $m / z=341$, strongly suggested the possible involvement of another oxidation pathway for quercetin, since protocatechuic acid has not been reported to derive from the decomposition of (f). In this case, formation of the quercetin/ $\mathrm{Cu}^{2+}$ complex (c) happened first, which led to quercetin oxidation through $2 \mathrm{H}^{+}$abstraction (Figure 7). Subsequent steps would include the formation of a quinone methide (d) and a hydro-derivative (e) as intermediates, yielding eventually compound (f), which is the 2-(hydroxybenzoyl)-2-hydroxybenzofuran-3(2H)-one (Figure 8).

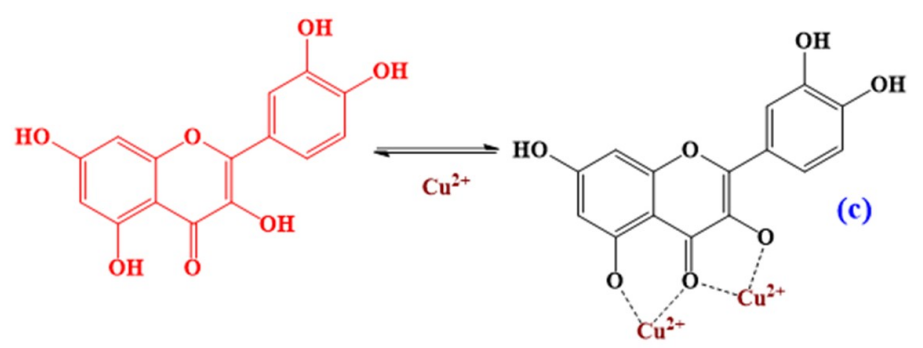<smiles>O=C1C(=O)c2c(O)cc(O)cc2[O+]=C1c1ccc(O)c(O)c1</smiles><smiles>O=C1C(=O)c2c(O)cc(O)cc2OC1=C1C=C(O)C(O)C(O)=C1</smiles><smiles>O=C1C(=O)C(O)(c2ccc(O)c(O)c2)Oc2cc(O)cc(O)c21</smiles><smiles>O=C1C(=O)C(c2ccc(O)c(O)c2)Oc2cc(Oc3ccccc3)cc(O)c21</smiles>

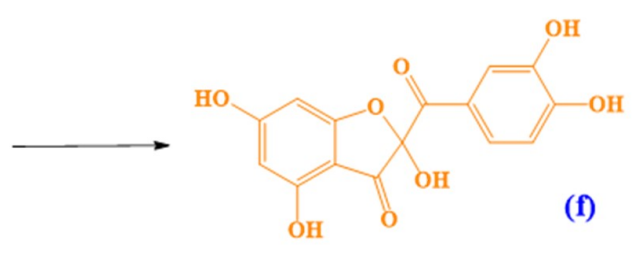

Figure 8. Putative pathway leading to the formation of the 2-(hydroxybenzoyl)-2hydroxybenzofuran-3(2H)-one. 


\section{Conclusions}

The kinetic investigation of $\mathrm{Cu}^{2+}$-induced quercetin oxidative degradation showed that it obeyed pseudo first-order kinetics irrespective of the presence of L-ascorbic acid and that the reaction was significantly affected by $T$. Modelling of the effect of L-ascorbic acid by deploying response surface methodology revealed that L-ascorbic acid did not have direct involvement, but its role in quercetin oxidation was implied by the putative pathways proposed. Therefore, an empirical pseudo first-order model was proposed, as a function of $T$ and $\mathrm{pH}$. The tentative identification of protocatechuic acid and 2-(hydroxybenzoyl)-2-hydroxybenzofuran-3(2H)-one suggested that, apart from a mechanism of $2 \mathrm{H}^{+}$ abstraction as a result of complexation with $\mathrm{Cu}^{2+}$, quercetin may be oxidised through the involvement of L-ascorbyl or other radicals (superoxide anion). Evidence also emerged indicating that the relevant reactions were rather $\mathrm{pH}$-dependent.

Author Contributions: N.B., A.P. and S.G., performed the experiments and analysed the raw data; D.P.M. conceived of and designed the experiments, handled the experimental data and wrote the paper.

Funding: This research was funded by International Centre for Advanced Mediterranean Agronomic Studies (CIHEAM).

Acknowledgments: International Centre for Advanced Mediterranean Agronomic Studies (CIHEAM) is acknowledged for funding this study.

Conflicts of Interest: The authors declare no conflict of interest.

\section{Nomenclature}

$k \quad$ first-order quercetin decay constant $\left(\mathrm{min}^{-1}\right)$

$C_{\mathrm{AA}} \quad$ L-ascorbic acid concentration $(\mu \mathrm{M})$

$E_{\mathrm{a}} \quad$ activation energy $\left(\mathrm{kJ} \cdot \mathrm{mol}^{-1}\right)$

$R \quad$ universal gas constant $\left(\mathrm{J} \cdot \mathrm{K}^{-1} \cdot \mathrm{mol}^{-1}\right)$

$T$ temperature $\left({ }^{\circ} \mathrm{C}\right.$ or $\left.\mathrm{K}\right)$

$t \quad$ time (min)

$t_{\frac{1}{2}} \quad$ half-life of quercetin ( $\left.\mathrm{min}\right)$

\section{References}

1. Wang, W.; Sun, C.; Mao, L.; Ma, P.; Liu, F.; Yang, J.; Gao, Y. The biological activities, chemical stability, metabolism and delivery systems of quercetin: A review. Trends Food Sci. Technol. 2016, 56, 21-38. [CrossRef]

2. Calani, L.; Dall'Asta, M.; Bruni, R.; Rio, D.D. Flavonoid occurrence, bioavailability, metabolism, and protective effects in humans: Focus on Flavan-3-ols and Flavonols. In Recent Advances in Polyphenol Research; Romani, A., Lattanzio, V., Quideau, S., Eds.; John Wiley \& Sons: Hoboken, NJ, USA, 2014; Volume 4, pp. 239-279.

3. Jan, A.T.; Kamli, M.R.; Murtaza, I.; Singh, J.B.; Ali, A.; Haq, Q. Dietary flavonoid quercetin and associated health benefits-An overview. Food Rev. Int. 2010, 26, 302-317. [CrossRef]

4. Zhou, A.; Sadik, O.A. Comparative analysis of quercetin oxidation by electrochemical, enzymatic, autoxidation, and free radical generation techniques: a mechanistic study. J. Agric. Food Chem. 2008, 56, 12081-12091. [CrossRef] [PubMed]

5. Makris, D.P.; Rossiter, J.T. Effect of natural antioxidants on heat-induced, copper (II)-catalysed, oxidative degradation of quercetin and rutin (quercetin 3-O-rutinoside) in aqueous model systems. J. Sci. Food Agric. 2002, 82, 1147-1153. [CrossRef]

6. Gülşen, A.; Turan, B.; Makris, D.P.; Kefalas, P. Copper (II)-mediated biomimetic oxidation of quercetin: generation of a naturally occurring oxidation product and evaluation of its in vitro antioxidant properties. Eur. Food Res. Technol. 2007, 225, 435. [CrossRef]

7. Gülşen, A.; Makris, D.P.; Kefalas, P. Biomimetic oxidation of quercetin: isolation of a naturally occurring quercetin heterodimer and evaluation of its in vitro antioxidant properties. Food Res. Int. 2007, 40, 7-14. [CrossRef] 
8. Fuentes, J.; Atala, E.; Pastene, E.; Carrasco-Pozo, C.; Speisky, H. Quercetin oxidation paradoxically enhances its antioxidant and cytoprotective properties. J. Agric. Food Chem. 2017, 65, 11002-11010. [CrossRef] [PubMed]

9. Cort, W.M. Antioxidant properties of ascorbic acid in foods. In Ascorbic Acid: Chemistry, Metabolism, and Uses; Seib, P.A., Tolbert, B.M., Eds.; American Chemical Society: Washington, DC, USA, 2007; Volume 200, pp. 533-550. ISBN 9780841206328.

10. Liao, M.-L.; Seib, P.A. Chemistry of L-ascorbic acid related to foods. Food Chem. 1988, 30, 289-312. [CrossRef]

11. Takamura, K.; Ito, M. Effects of metal ions and flavonoids on the oxidation of ascorbic acid. Chem. Pharmaceut. Bul. 1977, 25, 3218-3225. [CrossRef]

12. Beker, B.Y.; Sönmezoğlu, İ.; İmer, F.; Apak, R. Protection of ascorbic acid from copper (II)-catalyzed oxidative degradation in the presence of flavonoids: Quercetin, catechin and morin. Inter. J. Food Sci. Nutr. 2011, 62, 504-512. [CrossRef] [PubMed]

13. Mabry, T.J.; Markham, K.R.; Thomas, M.B. The ultraviolet spectra of flavones and flavonols. In The Systematic Identification of Flavonoids; Springer: Heidelberg, Germany, 1970; pp. 41-164.

14. Makris, D.P.; Rossiter, J.T. Heat-induced, metal-catalyzed oxidative degradation of quercetin and rutin (quercetin 3-O-rhamnosylglucoside) in aqueous model systems. J. Agric. Food Chem. 2000, 48, 3830-3838. [CrossRef] [PubMed]

15. Pękal, A.; Biesaga, M.; Pyrzynska, K. Interaction of quercetin with copper ions: complexation, oxidation and reactivity towards radicals. Biometals 2011, 24, 41-49. [CrossRef] [PubMed]

16. Hajji, H.E.; Nkhili, E.; Tomao, V.; Dangles, O. Interactions of quercetin with iron and copper ions: Complexation and autoxidation. Free Radic. Res. 2006, 40, 303-320. [CrossRef] [PubMed]

17. Jungbluth, G.; Rühling, I.; Ternes, W. Oxidation of flavonols with $\mathrm{Cu}(\mathrm{II}), \mathrm{Fe}(\mathrm{II})$ and $\mathrm{Fe}(\mathrm{III})$ in aqueous media. J. Chem. Soc. Perkin Trans. 2000, 2, 1946-1952. [CrossRef]

18. Jurasekova, Z.; Domingo, C.; Garcia-Ramos, J.; Sanchez-Cortes, S. Effect of pH on the chemical modification of quercetin and structurally related flavonoids characterized by optical (UV-visible and Raman) spectroscopy. Phys. Chem. Chem. Phys. 2014, 16, 12802-12811. [CrossRef] [PubMed]

19. Mocek, M.; Richardson, P.J. Kinetics and mechanism of quercetin oxidation. J. Inst. Brew. 1972, 78, 459-465. [CrossRef]

20. Wang, J.; Zhao, X.-H. Degradation kinetics of fisetin and quercetin in solutions as effected by $\mathrm{pH}$, temperature and coexisted proteins. J. Serb. Chem. Soc. 2016, 81, 243. [CrossRef]

21. House, J.E. Principles of Chemical Kinetics, 2nd ed.; Academic Press: Cambridge, MA, USA, 2007.

22. Samra, M.A.; Chedea, V.S.; Economou, A.; Calokerinos, A.; Kefalas, P. Antioxidant/prooxidant properties of model phenolic compounds: Part I. Studies on equimolar mixtures by chemiluminescence and cyclic voltammetry. Food Chem. 2011, 125, 622-629. [CrossRef]

23. Letan, A. The relation of structure to antioxidant activity of quercetin and some of its derivatives I. Primary activity. J. Food Sci. 1966, 31, 518-523. [CrossRef]

24. Hayakawa, K.; Minami, S.; Nakamura, S. Kinetics of the oxidation of ascorbic acid by the copper (II) ion in an acetate buffer solution. Bull. Chem. Soc. Jpn. 1973, 46, 2788-2791. [CrossRef]

25. Kimura, M.; Kobayashi, A.; Boku, K. Kinetic studies of the oxidation of L-ascorbic acid by the peroxodisulfate ion, and of copper (II)-catalysis. Bull. Chem. Soc. Jpn. 1982, 55, 2068-2073. [CrossRef]

26. Gutteridge, J.; Wilkins, S. Copper-dependent hydroxyl radical damage to ascorbic acid. FEBS Let. 1982, 137, 327-330. [CrossRef]

27. Kaizer, J.; Speier, G. Radical-initiated oxygenation of flavonols by dioxygen. J. Mol. Catal. A Chem. 2001, 171, 33-36. [CrossRef]

28. Kano, K.; Mabuchi, T.; Uno, B.; Esaka, Y.; Tanaka, T.; Linuma, M. Superoxide anion radical-induced dioxygenolysis of quercetin as a mimic of quercetinase. J. Chem. Soc. Chem. Commun. 1994, 0, 593-594. [CrossRef]

29. Osman, A.; Makris, D.P.; Kefalas, P. Investigation on biocatalytic properties of a peroxidase-active homogenate from onion solid wastes: An insight into quercetin oxidation mechanism. Process Biochem. 2008, 43, 861-867. [CrossRef]

30. Sokolová, R.; Degano, I.; Ramešová, Š.; Bulíčková, J.; Hromadová, M.; Gál, M.; Fiedler, J.; Valášek, M. The oxidation mechanism of the antioxidant quercetin in nonaqueous media. Electrochim. Acta 2011, 56, 7421-7427. [CrossRef] 
31. Zhou, A.; Kikandi, S.; Sadik, O.A. Electrochemical degradation of quercetin: Isolation and structural elucidation of the degradation products. Electrochem. Commun. 2007, 9, 2246-2255. [CrossRef]

32. Sokolová, R.; Ramešová, Š.; Kocábová, J.; Kolivoška, V.; Degano, I.; Pitzalis, E. On the difference in decomposition of taxifolin and luteolin vs. fisetin and quercetin in aqueous media. Monats. Chem. Chem. Mon. 2016, 147, 1375-1383. [CrossRef]

33. Zenkevich, I.G.; Eshchenko, A.Y.; Makarova, S.V.; Vitenberg, A.G.; Dobryakov, Y.G.; Utsal, V.A. Identification of the products of oxidation of quercetin by air oxygenat ambient temperature. Molecules 2007, 12, 654-672. [CrossRef] [PubMed]

34. Pham, A.N.; Xing, G.; Miller, C.J.; Waite, T.D. Fenton-like copper redox chemistry revisited: Hydrogen peroxide and superoxide mediation of copper-catalyzed oxidant production. J. Catal. 2013, 301, 54-64. [CrossRef]

(C) 2018 by the authors. Licensee MDPI, Basel, Switzerland. This article is an open access article distributed under the terms and conditions of the Creative Commons Attribution (CC BY) license (http://creativecommons.org/licenses/by/4.0/). 